\title{
Bill Magruder's Ship Comes Home
}

THOSE in Britain who proclaim that governments cannot adequately direct research should seriously ponder the way in which the United States Administration has for the third year tried-without much success so far-to make its expenditure on research and development more relevant-as the saying goes - to immediate needs. Two years ago, the budget of the National Science Foundation included a generous allocation of funds for the programme described as IRPOS-Interdisciplinary Research on Problems of Our Society. The disappointing discovery that suitable research proposals were alternatively unpointed or unglamorous led not to a retreat from the ambition to devise relevant research but to the National Science Foundation's programme called RANN-. Research Applied to National Needs. But the foundation overplayed its hand at the budget hearing last year, and also blotted its copybook with Congress by seeming cavalierly indifferent to the needs of the universities and of research students, with the result that much of the increase of its budget was unspendable. Not seriously dismayed, however, the Administration has now gone on to propose a budget for the coming financial year which is likely-if Congress can be brought to heel in this election year-to see substantial federal spending on specific projects in applied research including rapid transport systems, sources of clean energy, protection from natural disasters and the like. The universities will not see much benefit from the increased spending, for the amounts which the National Science Foundation has at its disposal for research and development will increase only from $\$ 409$ million to $\$ 455$ million. The bulk of the increased expenditure will be administered by the government departments, although there may be some welcome fall-out from the new cancer programme. And the President has yet to say how much extra money will be made available to Mr William Magruder's office in the White House for projects of applied research.

The implications of the new federal budget for science and technology are still obscure, but there is at least a serious danger that the penury which the universities have endured for the past three years may now be crippling. Although the Administration estimates that the National Science Foundation will have an extra $\$ 60$ million to spend in the coming financial year, very little of this will find its way to the universities. There is still a long way to go to the goal of $\$ 1,000$ million a year that Mr William D. McElroy said at the beginning of his term as chairman would be his minimum demand. But as the years have passed, the universities have understandably become more than ever dependent on the National Science Foundation for the support of students and research. That is as it should be, for the old notion that there is bound to be a degree of safety in a multiplicity of grant-giving agencies of the federal government has long since been discredited by the shrinking of NASA and of the AEC. Although the Administration may be right in saying that research must somehow be made to serve the community at large, its policies will come to nothing if the universities are unable to educate those without whom even applied research will not prosper.

The new budget is also shaky in its perpetuation of the space shuttle, sponsored by NASA. Gone are the days when the agency was rightly or wrongly committed to an objective-the landing of people on the Moon. Now, for practical purposes, it is committed merely to the construction of a machine, a device for carrying men to satellites in orbit about the Earth at a comparatively low cost. To safeguard this programme, plans have been dropped for sending rockets to distant planets, for completing the development of nuclear powered rockets and even for working out the ways in which the first stage of the shuttle vehicle could be returned to Earth and used again, originally the chief justification of this ambitious device. It must seriously be asked whether this assignment of priorities can be sensible. The men at NASA have consistently underestimated the benefits yet to be won from basic research within the solar system. It may always have been fanciful to expect that such things as Earth resources satellites could make a contribution to national and international life as important as telecommunications satellites, but it is mistaken to soft-pedal, as NASA is doing, the potential utility of knowing more about such things as the solar wind and even the nearby planets. By all appearances, for the sake of the shuttle, NASA is neglecting what it has become fashionable in Britain to call strategic research. If in Britain Rothschild has the edge on the Daintonites, there is good reason to think that Magruder needs a Dainton.

\section{Cadmium off Avonmouth}

THE flurry of excitement in the past week about the zinc smelting plant on the Avon is a splendid illustration of the kinds of issues into which environmentalists should sink their teeth. The plant is a technical innovation in the sense that the smelting process is carried out in a blast furnace, not by roasting the ore. In the two years since the plant has been in operation, it appears that the atmosphere within the factory has in some places been laden to an uncomfortable degree with lead. No doubt the operators, a subsidiary of the Rio Tinto Zinc corporation, are right when they claim that no workman has yet been damaged and that the limits set for zinc in the blood circulation have not been exceeded, yet it is bound to be a chancy business to make sure that no accidents will happen in circumstances in which the safety limits are as tightly drawn as they appear to be at Avonmouth. To be sure, it is a considerable benefit to all concerned that there are now laboratory techniques for telling where the threshold should be set. In the vulcanizing plants of the late nineteenth century, the only indices of risk were the overt symptoms of disease which the unfortunate workmen bore-and these were all too frequently regarded as 